\title{
Features of the Idea of University Students About Mental Health
}

Myroslava Kulesha-Liubinets

Elena Ruban

Vasyl Stefanyk Precarpathian National University, Ivano-Frankivsk, Ukraine

1. Relevance of research. Mental health, according to WHO, is a state of well-being in which a person is able to reach his or her own potential and overcome ordinary life stresses. Today, mental health disorders are in the top five of people's illnesses.

2. The following scientists have addressed the issues of mental health preservation: D. Bowen, L. Burlachuk, O. Vasilyeva, I. Galetska, S. Gluzman, V. Gorbunov, I. Dubrovina, V. Klimchuk, I. Koltunov, I. Kotsan, M. Kulesha-Liubinets, O. Malina, M. Mushkevich, L. Peretyatko, O. Haustova, O. Chaban and others.

3. At the present stage of development of Ukraine, special attention should be paid to the level of mental health awareness among students of higher education institutions. After all, excessive nervous and mental stress, inflated demands on oneself, insecurity in one's own future are the factors that worsen the mental health of the young people.

4. The aim of the study. Conduct an empirical study of university students' perceptions of mental health.

5. Research methodology and organization. The study sample consisted of 60 students of Vasyl Stefanyk Precarpathian National University, including: 20 students of the 2 nd year of specialty "Secondary education (history)", 20 persons of the 1st year and 20 students of 4th year of the specialty "Psychology". Among the respondents - 9 men and 51 women aged 19 years. All respondents were voluntarily surveyed.

6. To achieve the goal of the study we used the author's questionnaire.

7. $\quad$ Research results. The survey showed ambiguous understanding of the concept of "mental health" and its importance in life.

8. Future history teachers have described mental health as: "equilibrium," "adequate behavior," "self-acceptance," and more. At the same time, $40 \%$ of those polled classify mental health as "no mental disorder". Students of the first course of the specialty "Psychology" characterized mental health as: "level of psychological well-being", "satisfactory emotional well-being", "spiritual uplift" and others. Mental health was defined as "no mental disorder" by only $27 \%$ of students. Students of the 4th year of the specialty "Psychology" described "mental health" as: "psychological, social well-being", "harmony with oneself", "opportunity to realize their abilities", "acceptance of self" and others. However, no one defines mental health as the absence of mental disorders, which indicates a deeper understanding of it than the freshmen of the university.

9. The main ways of maintaining mental health in the opinion of young people are: meditation, sports, yoga, self-development. However, only half of the students surveyed (54\%) regularly play sports. 
10. The self-esteem of students of the level of formation of responsible attitude to health makes $6,8-7,3$ points (lower values were shown by freshmen); the level of relations with others - 7.0-7.4 points (higher rates of students of the 4th year, which testifies to the developed in them communicative qualities, ability to overcome conflict situations); the level of satisfaction with personal development - 7,0-7,5 points (lower level was noted by students of the 4th year, which, in our opinion, can indicate an increase in the level of harassment).

11. Psychological stress was assessed by students at 3.7-5.0 points (low level of students in the specialty "Secondary education (history)"). Observations show that these students are more cohesive and confident about their profession. This thesis is confirmed by the determination of the level of happiness of students: future teachers of history - it is 7.8 unlike the students of specialty "Psychology" 4 year, who noted their own happiness at 7.2.

12. Conclusions. Thus, university students are not sufficiently informed about the content of mental health. Future fourth-year psychologists who have completed courses in Clinical Psychology, Pathopsychology, etc., as well as practice in hospitals, are more aware of the importance of maintaining mental health as opposed to freshmen and students in other specialties. Therefore, it is important for the university to carry out educational work to promote mental health 